Musées, Patrimoine et Culture scientifiques et techniques

$184 \mid 2019$

juillet-août 2019

\title{
Séduire et capter les publics
}

Katy Tari

URL : http://journals.openedition.org/ocim/2976

DOI : $10.4000 /$ ocim.2976

ISSN : 2108-646X

Éditeur

OCIM

Édition imprimée

Date de publication : 1 juillet 2019

Pagination : 38-45

ISSN : 0994-1908

Référence électronique

Katy Tari, « Séduire et capter les publics », La Lettre de l'OCIM [En ligne], 184 | 2019, mis en ligne le 01

juillet 2020, consulté le 25 janvier 2021. URL : http://journals.openedition.org/ocim/2976 ; DOI :

https://doi.org/10.4000/ocim.2976

Ce document a été généré automatiquement le 25 janvier 2021.

Tous droits réservés 


\section{Séduire et capter les publics}

\section{Katy Tari}

Les nocturnes du musée d'Art contemporain de Montréal sont devenues un événement couru auprès des jeunes adultes branchés: DJ, bar et buffet, ouverture des expositions jusqu'à $2 \mathrm{~h}$, ateliers de création de $18 \mathrm{~h}$ à $24 \mathrm{~h}$ sont au programme.

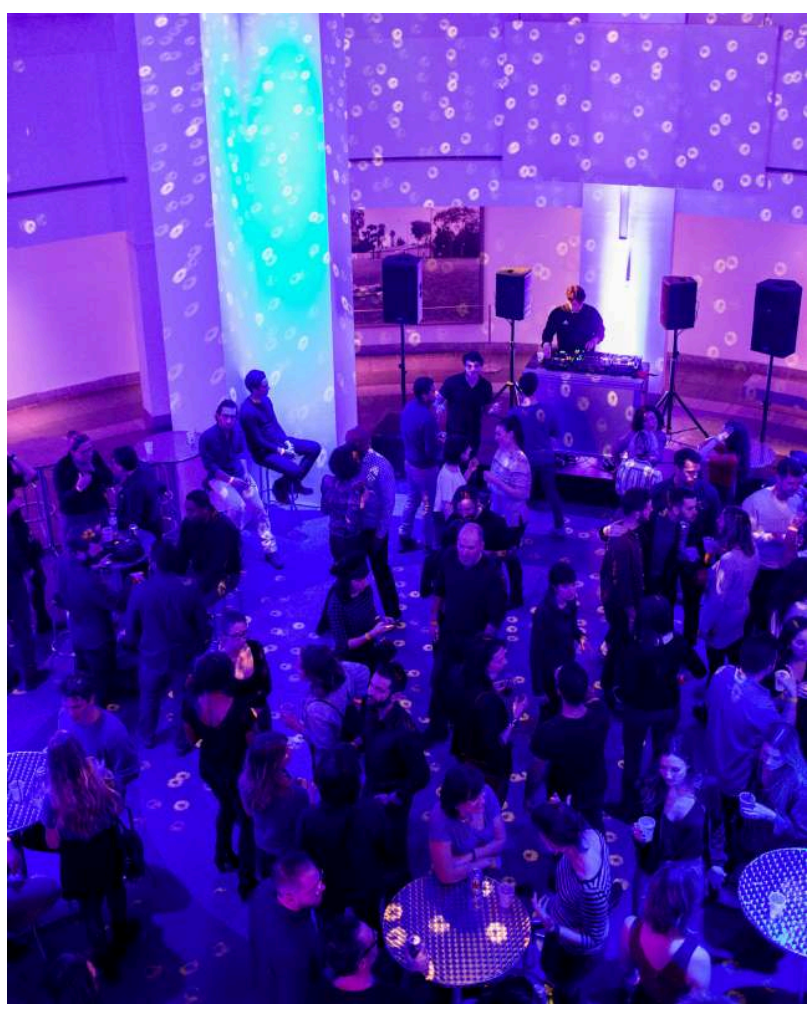

(c) Musée d'Art contemporain de Montréal/Sébastien Roy

L'offre culturelle au Québec est riche, abondante et se déploie largement à travers son territoire. Le milieu muséal n'échappe pas à cette équation et participe activement à la multiplication d'une offre variée et originale dans une perspective d'accessibilité et de valorisation culturelle. En tant que praticienne du secteur muséal depuis plus de 25 ans, je me suis intéressée à cette vitalité que l'on perçoit notamment depuis quelques années afin de comprendre comment cette réalité se traduit sur le terrain. 
1 L'année 2017 marque un sommet inégalé en termes de fréquentation muséale. Grâce notamment aux festivités liées au $275^{\mathrm{e}}$ anniversaire de Montréal, au $150^{\mathrm{e}}$ anniversaire de la Confédération canadienne et au 50 anniversaire d'Expo 67, 2017 constitue une année record sur le plan des entrées, avec 16,9 millions de visiteurs ${ }^{1}$. Par ailleurs, depuis une décennie, on constate un bond dans la fréquentation extra-muros des musées passant de 0,3 million d'entrées en 2008 à plus de 1,4 million en 2017. Les musées multiplient leurs efforts d'action culturelle pour rejoindre leurs publics.

\section{Une offre culturelle abondante}

2 Présents sur presque tout le territoire, les musées québécois suscitent un engouement populaire qui ne se dément pas. Ainsi, avec près de 420 musées pour 5,4 habitants au $\mathrm{km}^{2}$, la consommation culturelle des musées est en augmentation constante auprès de tous les publics. En se regroupant au sein de la Société des Musées du Québec, les membres du milieu québécois se sont dotés de tous les outils leur permettant de renouveler et d'enrichir leur offre muséale. Tout ceci a contribué à ce que le public afflue, passant de 11 millions d'entrées en 2006 à près de 17 millions d'entrées en $2017^{2}$. Un tel engouement ne saurait néanmoins se résumer à cette seule réalité statistique, tout aussi positive soit-elle. Car, derrière ces chiffres d'affluence se cache un monde à découvrir, ou plutôt un monde muséal en exploration constante qui redouble d'efforts afin d'attirer, de séduire voire de fidéliser les publics. Cet essor est en partie attribuable au renouvèlement des équipements, au dynamisme et à la créativité de ses professionnels et gestionnaires et à la mise en place de programmes évènementiels d'une rare qualité pour une programmation qui saura plaire et attirer les visiteurs ${ }^{3}$. 
Les collections en ligne du musée de la Civilisation à Québec sont en pleine croissance et intègrent la culture participative et collaborative. Le tout nouveau MLab s'inscrit en continuité avec cette approche dans une relation nouvelle avec les publics.

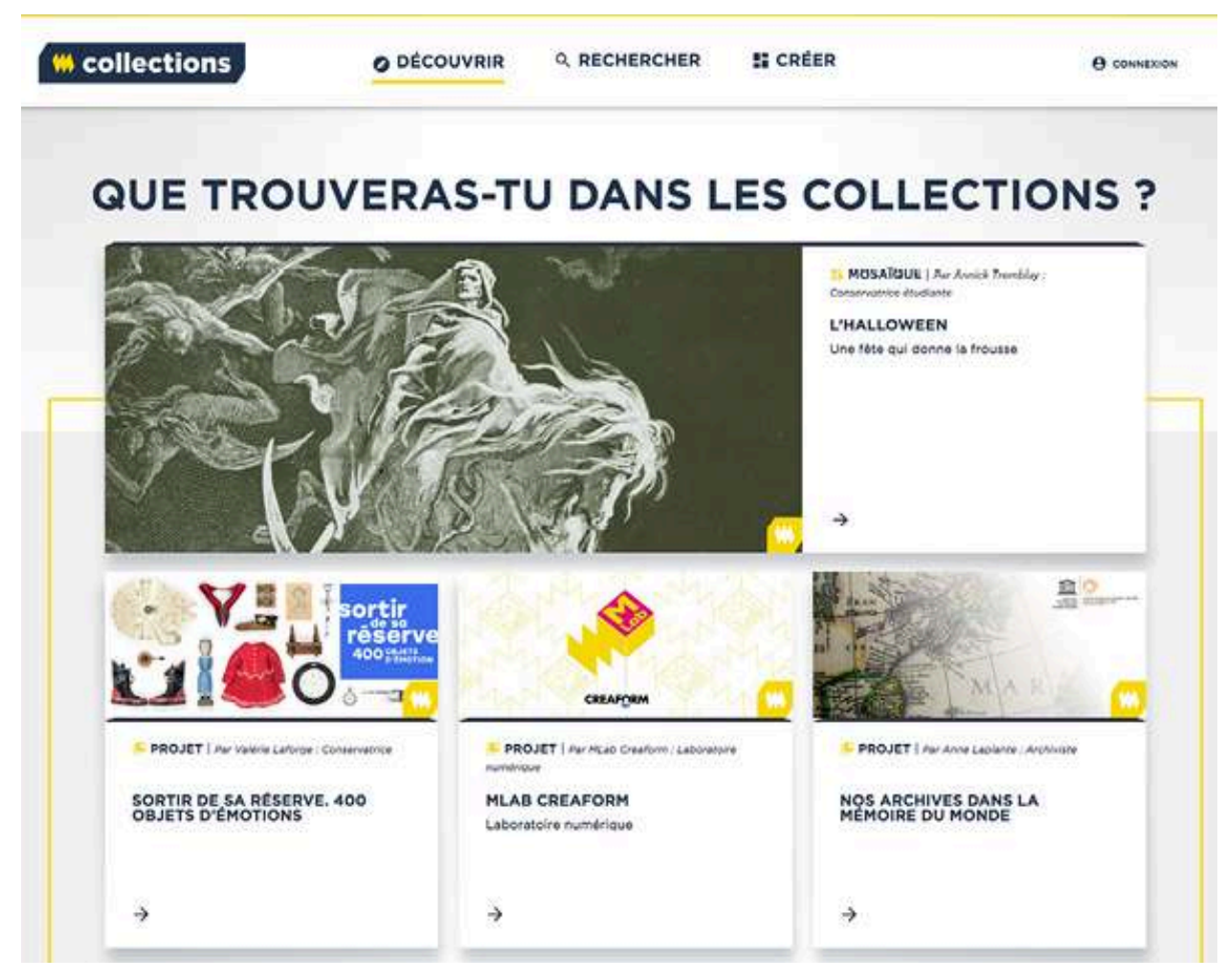

() Musée de la Civilisation

3 Démocratiser la culture induit pour le réseau muséal le déploiement d'une programmation culturelle variée, ponctuée par les saisons et l'évènementiel tels que les Journées de la culture, Culture pour tous, la Journée des musées. Mais ce qui émerge est le foisonnement d'activités qu'elles soient intra-ou extra-muros, parfois gratuites tels des concerts, des soirées pour les jeunes et autres évènements incontournables. Les musées s'exposent aux tendances, créent des occasions de rencontres, des festivités et des actions culturelles afin d'être concurrentiels et attrayants tout en inventant de nouveaux modèles d'affaires pour les clientèles de proximité et les communautés locales. Ainsi, des programmes innovateurs sont instaurés pour attirer par divers moyens les visiteurs tant au sein de leurs murs qu'extra-muros. Les résultats de fréquentation enregistrés confirment que cette approche est payante pour eux et que la perception des musées se transforme en espaces publics intégrés aux communautés qu'elles investissent.

\section{Un état des lieux}

Premier constat, le réseau muséal québécois est extrêmement diversifié sur le plan disciplinaire avec ses musées, centres et lieux d'interprétation dévolus à l'histoire, l'art ou encore les sciences et techniques. Ce foisonnement d'institutions muséales et culturelles traduit un dynamisme et une transformation des approches qui se sont opérés depuis les dernières décennies en dépit d'une conjoncture financière complexe. Deuxième constat, l'environnement culturel est massivement dominé par les industries 
culturelles, le cinéma, les multiples festivals et spectacles qui accentuent la pression sur les institutions muséales pour être attractives. Fort heureusement, les statistiques de fréquentation des musées révèlent qu'en 30 ans, la proportion de la population allant au musée s'est sensiblement accrue. En effet, alors qu'on enregistrait $31 \%$ en 1979, les résultats révèlent que cette proportion s'élevait à $42 \%$ en 2004 et même $44 \%$ en $2014^{4}$. Une effervescence nouvelle semble émerger pour attirer les visiteurs vers les musées.

\section{La muséo-séduction pour les non-publics}

Pour Annette Viel : «Toute mise en valeur... vise à provoquer une rencontre intime et vivante entre les visiteurs et la ressource. Une rencontre à créer, à orchestrer... entre la ressource à la fois signifiante et signifiée $\|^{5}$.

Aborder les non-publics consiste à identifier des nouveaux repères pour provoquer cette rencontre avec le musée. L'enjeu consiste à cerner des publics potentiels à la fois insaisissables et accessibles en autant que l'on parvienne à les séduire et à les attirer. Qui sont-ils et comment les aborder ? En 2004, on enregistrait un taux de $55 \%$ de la population québécoise ayant fréquenté une institution patrimoniale versus $45 \%$ avouant ne pas en avoir fréquenté. Pour le secteur muséal, ces taux passaient de 31,2\% en 1979 à 41,7 \% en 2004 pour ceux admettant ayant fréquenté un musée, représentant un gain significatif ${ }^{6}$ et que l'on peut soupçonner s'être accru depuis. Bien que ces résultats ne fournissent qu'une estimation de l'intérêt manifesté pour les musées, le non-public, pour sa part, ne saurait être réduit à un groupe homogène. La conquête de ces publics passe au moins par leur segmentation et peut se décliner par une pluralité de critères liés au lieu, à l'unité de temps, à la rareté et à l'exclusivité ou au genre. Pour Laurent Fleury (2011) le non-public est composé de tous les individus qui n'ont ni accès ni aucune chance d'accéder à la culture ${ }^{7}$. Ainsi, peut-il s'agir de publics n'ayant pas les moyens ni le temps, ou encore de publics ayant plutôt un intérêt pour une culture dite commerciale, ou étant en quête de lieux de socialisation. En interrogeant de manière plus ciblée les intérêts potentiels de ces non-visiteurs, il devient alors possible d'identifier leurs besoins puis de caractériser des offres provoquant la rencontre de publics là où ils sont. Dans cette perspective, il est intéressant d'observer la diversité des formes des propositions évènementielles et des actions culturelles émergeantes dans les musées. 
Au musée maritime du Québec, les visiteurs peuvent marcher dans la zone de l'estran entre le parc maritime du musée et le Rocher Panet : une nouvelle expédition amusante dans les battures fluviales de la côte du Sud du Saint-Laurent qui intègre également un contenu historique.

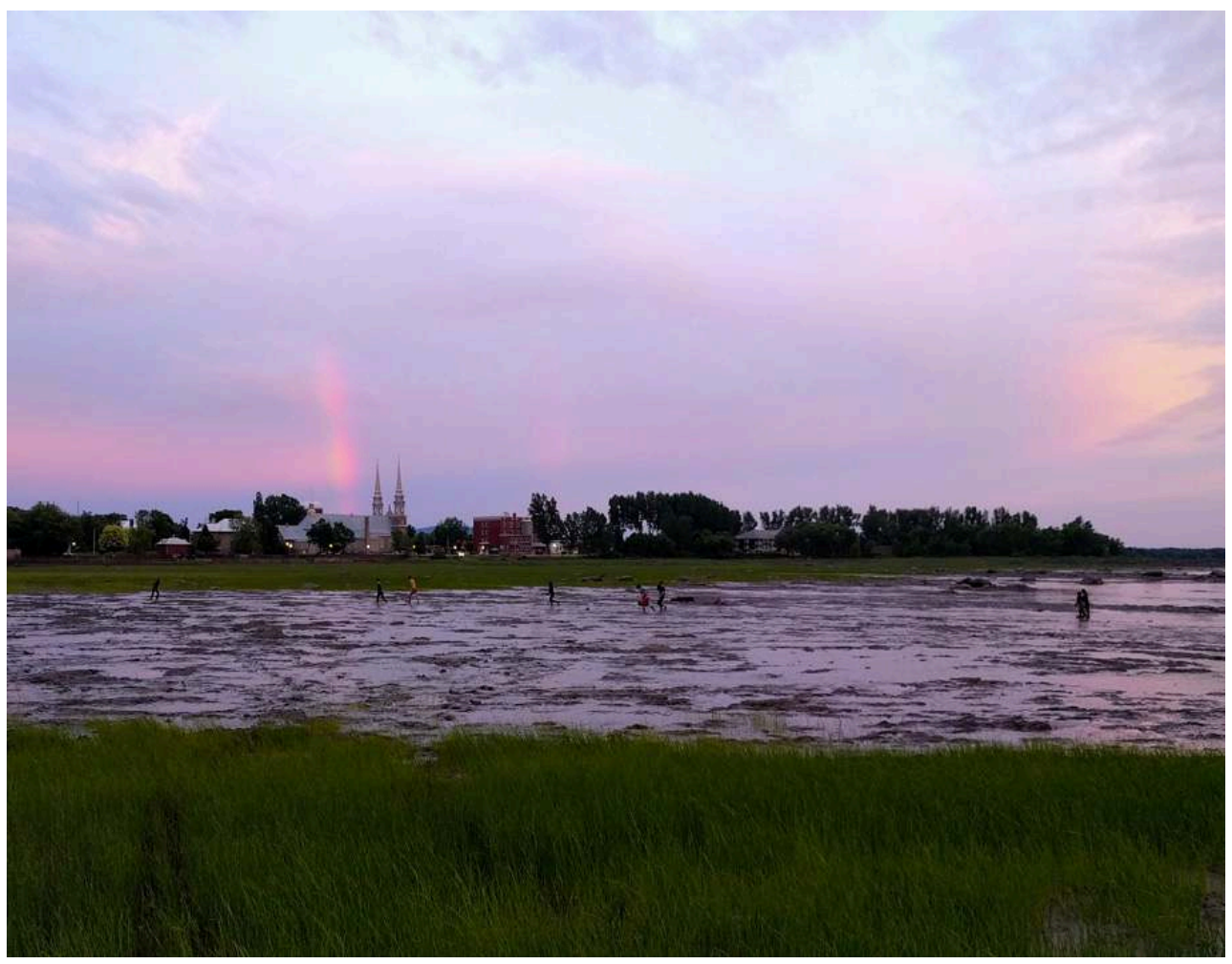

(c) Sophie Royer

\section{Faire vivre une expérience}

7 Face à des publics de plus en plus exigeants et déjà fortement sollicités par de multiples offres culturelles, la mise en scène de l'expérience est devenue le nouveau parangon. Ce qu'elle sous-tend est surtout de libérer le musée des traditions, de dépoussiérer l'image que l'on en a pour focaliser sur l'effet de surprise, l'unicité et le ressenti. Cette dynamique évolue constamment et implique bien sûr l'excellence et la recherche d'authenticité, mais surtout l'expérimentation, l'étonnement. En somme, la recherche de l'effet d'émulation, le « wow » qui fera s'enthousiasmer et trouvera écho. À l'instar de Nina Simon ${ }^{8}$, les visiteurs recherchent à satisfaire leurs besoins lorsqu'ils viennent au musée : quel gain de sens feront-ils et quel niveau d'efforts devront-ils déployer pour vivre leur expérience puisque les publics sont à la recherche de sens et d'interaction signifiante pour eux?

8 À image forte, empreinte forte. La scénographie est centrale et porteuse de sens. Quand celle-ci est pensée et intégrée au point d'incarner le discours ou le propos de l'exposition, l'on prend toute la mesure de son impact et de sa force par l'empreinte qu'elle laisse auprès du visiteur. Par la muséographie, il est possible de réinventer l'expérience muséale en marquant les esprits, suscitant une rencontre, dans la mise en scène des contenus liés à la thématique présentée. Créer un sentiment d'exclusivité pour que le public se souvienne d'avoir vécu un moment privilégié au musée. 


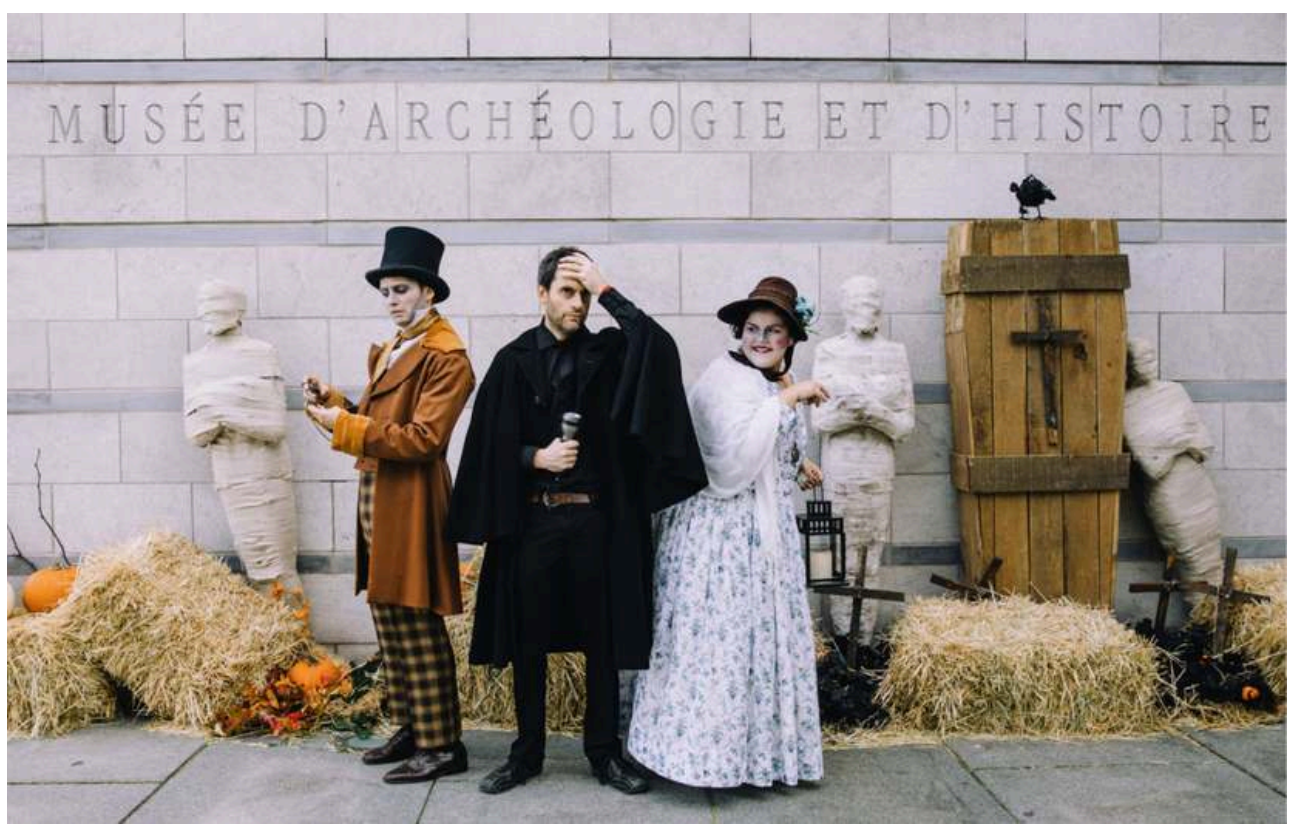

(c) Geneviève Giguère

\section{Miser sur l'authentique}

Une autre stratégie porteuse consiste à exposer l'authentique tout en misant sur le sens à donner aux objets. Le site du Fort de Ville-Marie à Pointe-à-Callière ${ }^{9}$ est à ce titre exemplaire dans son effort de mise en valeur des vestiges. Sous le plancher de verre, les sols et les vestiges se dévoilent bien et ce même s'ils sont fragmentaires. Pour faire revivre les objets artefacts et écofacts témoins de plusieurs époques et souvent fragmentaires, une stratégie de déploiement les met en contexte avec une reconstitution en impression 3D.

Les expositions temporaires créent, pour leur part, l'évènement que ce soit autour de sujets connus ou encore par le biais d'angles accrocheurs qui feront tendance. L'interdisciplinarité a fait ses preuves et favorise l'émergence d'idées novatrices, de regards croisés et l'exploration d'idées nouvelles. Ce faisant, ces approches transforment le rapport aux objets en les décloisonnant. Les musées, comme lieux d'authenticité, cultivent ainsi l'innovation et la créativité tout en misant sur la création de sens.Les Quartiers disparus, une exposition-documentaire présentée au Centre d'histoire de Montréal, a permis de faire revivre trois quartiers disparus (le Red Light, le Faubourd à m'lasse et Goose Village) entre 1950 et 1975 pour moderniser la Ville. Les témoignages font redécouvrir une vie insoupçonnée dans ses mises en scène qui recréent la mémoire de ces lieux.

\section{La prévalence de l'évènementiel}

11 La médiation culturelle est essentielle au dynamisme des musées et s'inscrit dans un contexte actuel de mutation des pratiques et d'une tendance vers la diversification. Elle 
s'impose comme un modèle d'action privilégié dans le but avoué d'élargir les segments des publics. Renforcer l'action et s'engager dans l'événementiel revient à proposer une alternative à l'offre traditionnelle avec des temps forts. Ainsi, rejoindre plus de public équivaut à un public élargi et donc potentiellement des non-publics. L'on observe une volonté d'explorer du côté des performances, de la création ou de genre artistiques inusités tout en misant sur une cohérence avec la mission organisationnelle.

Citons la thématique de la visite-expérience telle que celle de la prison au musée de culture populaire de Trois-Rivières où l'on propose des témoignages sur la vie carcérale. Pour les amateurs de sensation forte la Sentence d'une nuit est l'occasion d'expérimenter la vie carcérale en passant une nuit dans une cellule authentique comme un vrai prisonnier. Dans un tout autre spectre, le Monastère-Musée des Augustines se définit comme une aventure pour soigner le corps et l'âme et propose une expérience de santé globale dans un lieu chargé d'histoire et de tradition. On peut y dormir pour un séjour monastique au cœur même du Monastère. Les aménagements de parcs thématiques tels que le parcours nocturne illuminé Foresta Lumina (2014) de $2 \mathrm{~km}$ inspiré de contes et de légendes de la région au Parc de la Gorge de Coaticook entrainent les visiteurs dans une expérience immersive. Devenu un incontournable estival de la région estrienne, Foresta Lumina connaît un succès de foule qui ne se dément pas et qui s'est exportée au Zoo de Saint-Félicien qui offre pour sa part Anima Lumina, un parcours nocturne multimédia dans la forêt boréale.

Depuis 2014, le parc de la Gorge de Coaticook propose Foresta Lumina, un parcours-expérience nocturne avec scénographie sonore et lumineuse développée en partenariat avec Moment Factor.

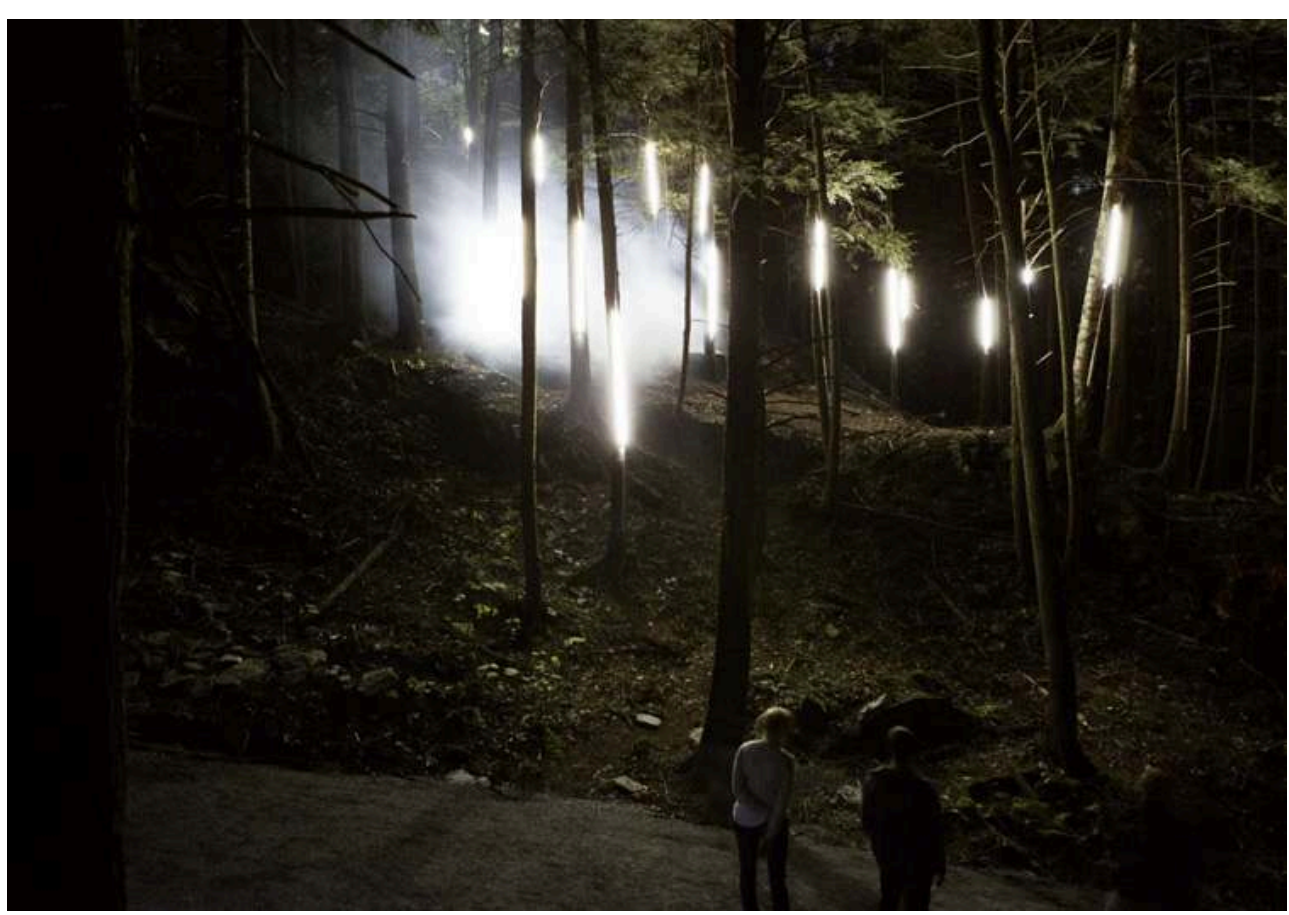

(c) Parc de la Gorgede Coaticook 


\section{L'expérience gustative}

13 D'autres modes de médiation inusités misent sur des rendez-vous qui stimulent d'autres sens, notamment celui du goût. Repas gastronomiques extérieurs (Jardins de métis), dégustations de vins ou de bières, le programme de Fourchette bleue pour une saine gestion des ressources marines du fleuve Saint-Laurent dans une perspective durable et de protection de la biodiversité lancée par Exploramer, l'expérience culinaire ou gustative est entrée dans le musée. Elle est une occasion de dégustation, de socialisation, de découverte et de participation active, voire de développement durable.

\section{Le numérique, un incontournable}

14 Présent dans plusieurs sphères d'activités, le milieu muséal, à l'instar de l'ensemble du milieu culturel, investit le monde du numérique et des communications. En développant des contenus par le biais du numérique, que ce soit l'accès aux collections, à l'élaboration de contenus éducatifs, ou encore dans la mise en place d'expérimentations en lien avec les expositions et les publics, les musées explorent et investissent cet espace socio-numérique. Ainsi, voit-on émerger dans les musées la conception d'expériences originales et immersives à des fins expérimentales ou s'imposant dans la muséographie des expositions et ce, alors que le public recherche ces nouveaux modes de communication : que ce soit pour interagir, participer ou partager, l'attrait du numérique pour les publics est indéniable en autant qu'il demeure pertinent et serve un propos.

15 À ce titre, les technologies contribuent à enrichir l'expérience et plongent le public dans un univers en interrelation. Qui plus est, l'expérience immersive favorisée par les technologies crée une rupture avec le quotidien et procure le sentiment d'être acteur en plus de spectateur. Des expériences immersives de réalité virtuelle telle que Le dernier voyage de l'Empress of Ireland lancé en 2013 (Site historique de la Pointe-auPère) et la Gaspésienne no. 20 inauguré en 2017 (musée de la Gaspésie) sont des formules gagnantes pour ces institutions qui ont vu leur visitorat sensiblement s'accroître. Le musée canadien de l'Histoire a pour sa part choisi d'intégrer les technologies de manière plus dépouillée par des dispositifs intégrés aux expositions. Un magnifique exemple de reconstitution faciale numérique en 3D grandeur nature alliant la recherche et les technologies. Produite par le musée en partenariat avec la communauté Shishalh à partir de restes humains de plus de 4000 ans retrouvés en 2010 près de l'actuel Sechelt en Colombie-Britannique, le résultat de cette projection est frappant et empreint de réalisme avec la présentation de cette famille quasi-vivante face au visiteur. À Pointe-à-Callière, les artefacts issus des fouilles archéologiques effectuées sur le site du Fort de Ville-Marie puis celles du site du Parlement du CanadaUni font l'objet de modélisation 3D permettant de les visualiser à leur emplacement précis. De telles recherches contribuent à l'avancement des connaissances historiques de ces sites historiques et favorisent une visualisation dans l'espace propice à la compréhension volumétrique des lieux. Dans un autre exemple plus ludique et contemplatif, le musée des Beaux-Arts de Montréal propose dans une de ses salles une expérience sylvestre immersive alors que le visiteur contemple des œuvres de paysages. En stimulant les sens, le visiteur entre en transe avec cet environnement à la fois apaisant et beau. 
Les collections en ligne prennent un nouveau virage et participent à la culture participative et s'inscrivent aussi dans la logique de l'expérience utilisateur : accès à l'information, multiplication de fonctionnalités diverses, utilisation ouverte et libre des données. Les musées qui le peuvent cherchent à investir la culture en ligne et à donner vie aux collections.

Le musée de la Gaspésie fait revivre un objet patrimonial : quoi de plus invitant que de plonger dans la réalité virtuelle pour faire revivre le dernier bateau de pêche à la morue, la Gaspésienne no. 20 .

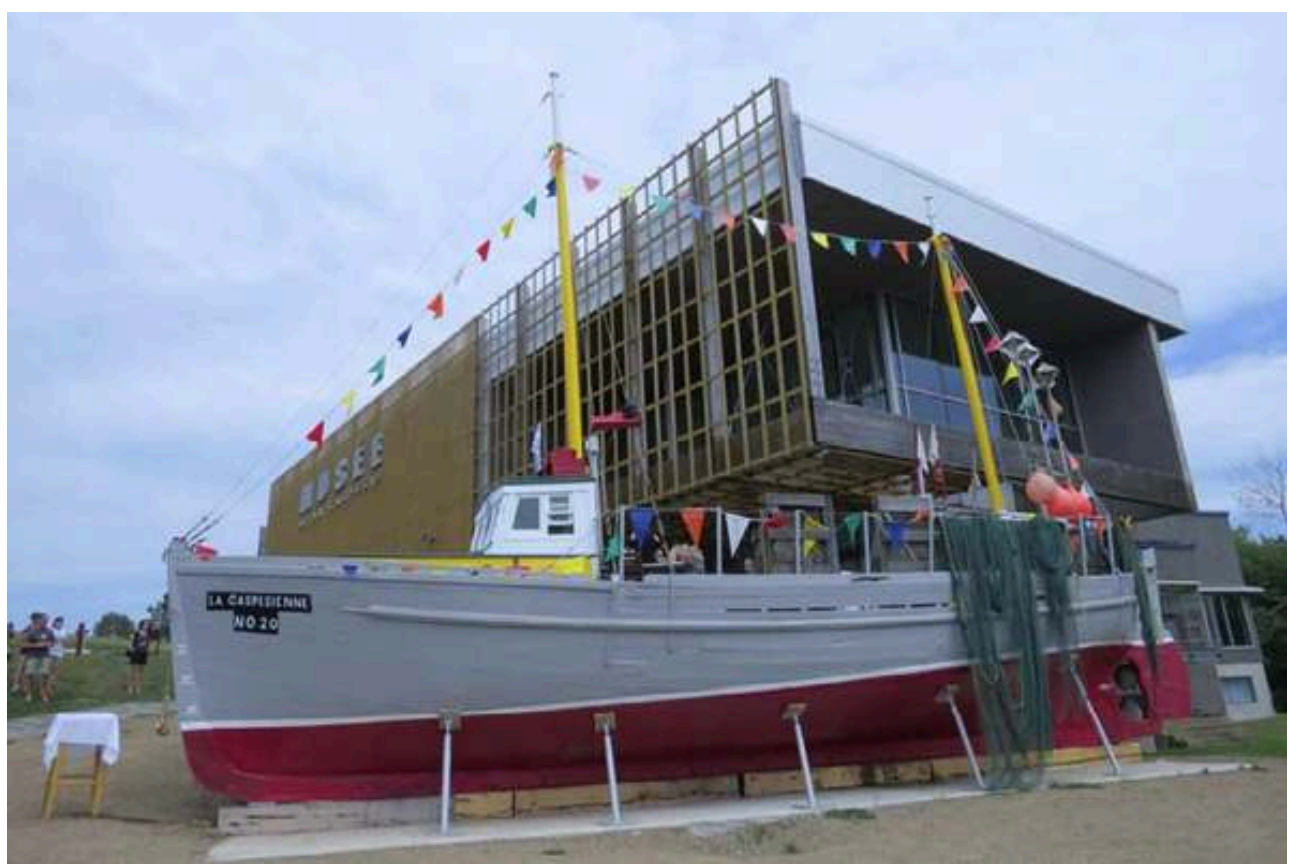

(c) Musée de la Gaspésie/Marc-André Aubé

Le musée de la Gaspésie fait revivre un objet patrimonial : quoi de plus invitant que de plonger dans la réalité virtuelle pour faire revivre le dernier bateau de pêche à la morue, la Gaspésienne no. 20 .

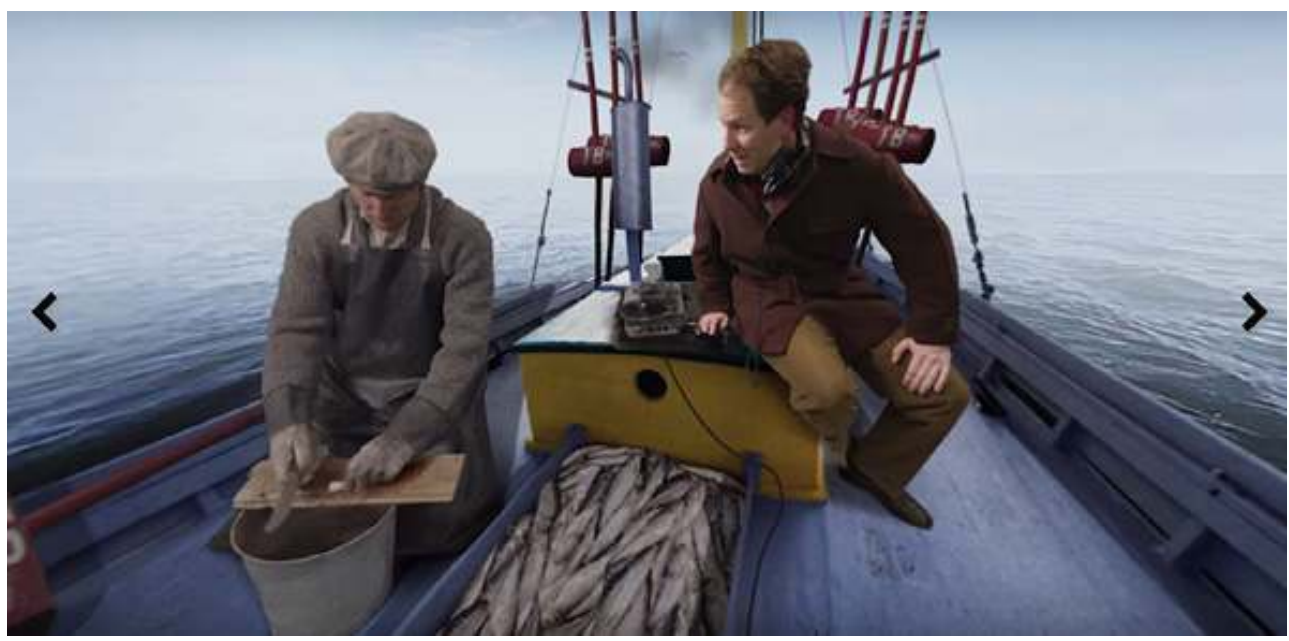

(c) Idée au Cube - TKNL 


\section{L'inclusion pour tous}

17 La mixité socioculturelle constitue une autre action de rencontre de l'autre, qu'il s'agisse de la valorisation de la diversité culturelle ou du mieux-être ensemble pour contrer l'exclusion sociale. L'axe communautaire dans des projets de réhabilitation, comme l'agir par l'imaginaire avec des groupes tels que les Impatients, sont quelquesunes des actions qui émergent. L'atelier international d'éducation et d'art-thérapie, développé depuis peu par le musée des Beaux-Arts de Montréal, allie l'art-thérapie, le mieux-être et l'inclusion avec ses espaces créatifs, des visites-thérapies ou d'autres activités visant à briser l'isolement des personnes souffrant de maladies mentales. Il démontre ce que peut faire un musée dans une société. La médiation culturelle peut soutenir le partage dans un processus de transmission en jetant des ponts entre la culture et la société.

À Pointe-à-Callière, les dimanches-famille de la rue piétonne du musée et le marché public dans l'ambiance du XVIII siècle attirent la foule des visiteurs.

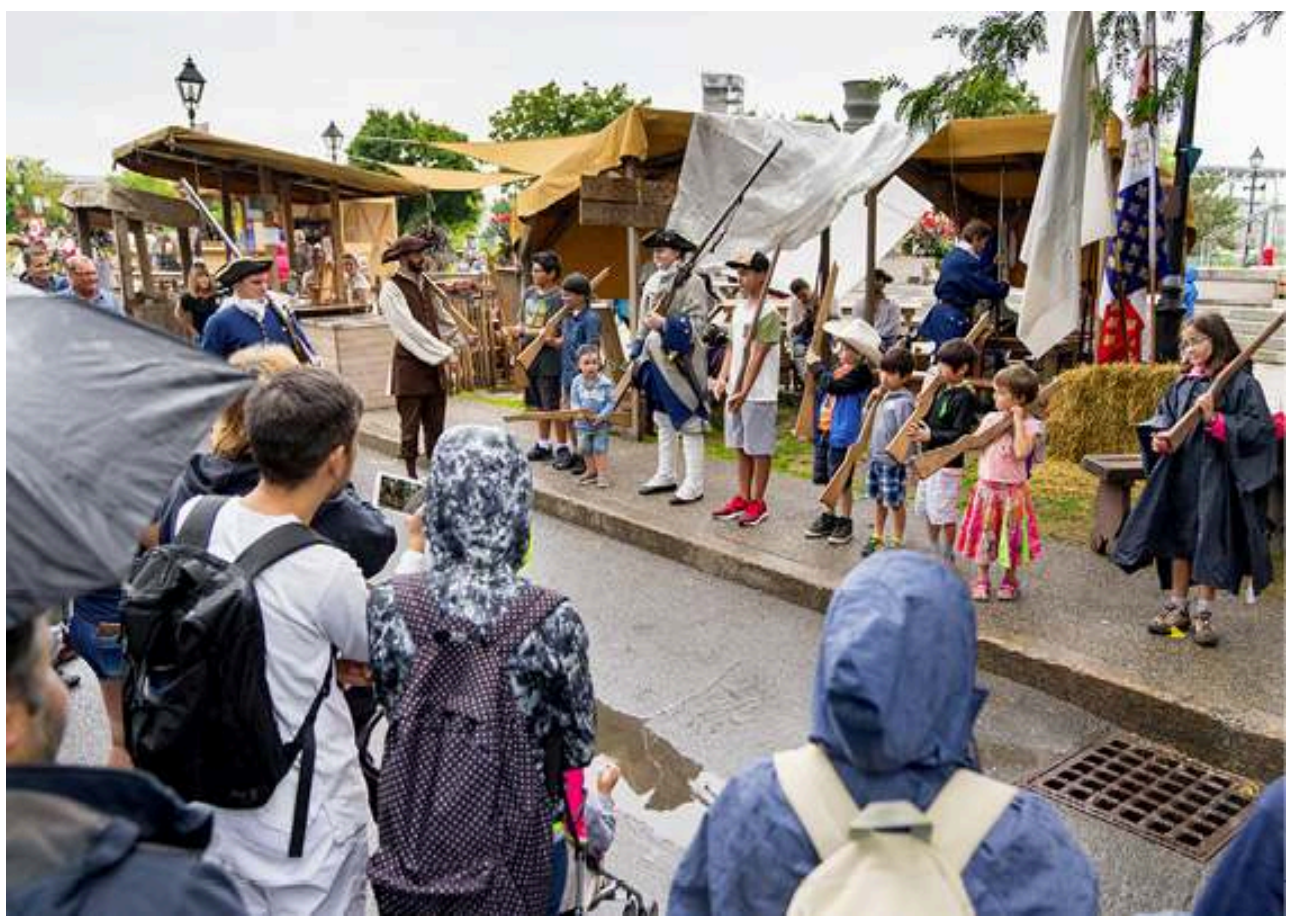

(c) Jean Michael Simario

\section{Jeune et branché}

Les jeunes publics recherchent à vivre une expérience dans d'autres lieux de socialisation ou d'expression. Ils sont à la recherche d'un sentiment de bien-être et de détente, et ils recherchent des activités dynamiques et actives pour interagir, discuter et s'amuser ${ }^{10}$, si bien que le musée n'est peut-être pas spontanément la réponse à leurs besoins. Or, depuis quelque temps, certains musées créent des évènements branchés dans leurs murs, via des nocturnes avec DJ, bar et bouchées (musée d'Art contemporain de Montréal) ou soirées Geek (Boréalis) qui répondent directement à leurs besoins. Le musée n'est plus seulement un lieu de diffusion, mais un lieu perçu par eux comme 
branché et connecté. Ailleurs, des activités festives tels les midis-musique pour les travailleurs du quartier (McCord, Pointe-à-Callière), les dimanches-familles, des marchés publics historiques à Pointe-à-Callière allient l'histoire et la vie contemporaine pour le plus grand bonheur des participants.

En somme, le musée sort de ses murs, s'éclate et redéfinit son rôle et sa place pour une clientèle plurielle et variée. Le musée se profile comme un lieu vivant, moderne et attractif : il est une expérience, authentique en prime. Le tourisme culturel est influencé par les tendances de mélange des genres, la recherche d'émotion, du « spect'acteur » et du lien social pour un visiteur connecté.

La muséologie de performance n'est pas nouvelle et déjà plusieurs auteurs entrevoyaient une tendance émergente. Lampugnani notait dès 2006 que " le musée développe d'innombrables activités concomitantes. Cette sorte d'activité frénétique fait partie intégrante de la programmation; le musée est désormais un lieu où la culture est exploitée afin de générer des revenus $»^{11}$. Aujourd'hui, on ne parle plus de tendance mais d'une réalité bien ancrée qui participe au décloisonnement du musée et d'un lieu pensé pour l'expérimentation.

\section{BIBLIOGRAPHIE}

Bellavance, G. Affronter les nouvelles dynamiques culturelles. Réflexions sur le Québec ou comment dépasser la question de la démocratisation, Démocratisation culturelle : l'intervention publique en débat, $\mathrm{n}^{\circ} 947$, avril 2008, pp. 107-112.

Cauclare, C. Les événements culturels : Essai de typologie. Ministère de la Culture, DEPS, Culture études, $n^{\circ} 3,2009 / 3$, pp. 1-8.

Dubuc, L. Innovation et créativité des territoires : Le cas du quartier des spectacles à Montréal. Université de Montréal, Travail de session, septembre 2016, 49 p.

Garcin-Marrou, F., Mairesse, F. et Mouton-Rezzouk, A. (dir.) Des lieux pour penser : musées théâtres bibliothèques, Matériaux pour une discussion. Icom, Icofom, 2018.

Lafortune, J.-M. De la démocratisation à la démocratie culturelle : dynamique contemporaine de la médiation culturelle au Québec, Démocratiser la culture, Une histoire comparée des politiques culturelles, sous la direction de Laurent Martin et Philippe Poirrier, Territoires contemporains, nouvelle série $n^{\circ} 5,2013$.

Leclerc, G. Une expérience ou rien? Qu'est-ce qui motive les publics culturels ? Culturecom, 23 novembre 2015.

Martin, T. Les logiques d'interprétation des enfants selon leur expérience de visite dans les musées de sciences et dans le cadre des loisirs, Recherches, vol. 30/2, 2012.

Montpetit, R. Une muséologie québécoise dynamique et d'aujourd'hui : favoriser l'appropriation des collections par les publics de maintenant. Ministère de la Culture et des Communications du Québec, 19 août 2013, 71 p. 
Nadeau, M.-P. Les non-publics des musées d'art : les raisons du désintérêt chez les 15-24 ans. Mémoire présenté à l'université du Québec à Trois-Rivières, décembre 2016.

Société des musées québécois, Étude sur les pratiques muséales en éducation, action culturelle et médiation, novembre 2016, $53 \mathrm{p}$.

\section{NOTES}

1. Le Québec, chiffres en main, 2017. 21 institutions dans la région de Montréal, 19 dans la région de Québec, 60 dans les autres régions.

2. Le Québec, chiffres en main, 2017. + Optique culture 60.

3. https://buzzles.org/2018/01/12/les-secrets-des-musees-pour-attirer-toujours-plus-devisiteurs-1-2/

4. Survol, Bulletin de la recherche et de la statistique, $\mathrm{n}^{\circ} 27$, mars 2016. Enquête sur les pratiques culturelles au Québec 2014.

5. Viel, A. De séduction et de muséologie, La Lettre de l'Ocim, n54, 1997.

6. État des lieux du patrimoine des institutions muséales et des archives, Le public des institutions patrimoniales, cahier 9, 2010, p.35. Site consulté : www.stat.gouv.qc.ca/statistiques/ culture/patrimoine-musees-archives/cahier-09-etatdeslieux.pdf

7. Fleury, L. Sociologie de la culture et des pratiques culturelles : Domaines et approches. Poches, 2011.

8. Simon, N. The Art of Relevance, 2016, www.artofrelevance.org.

9. Pointe-à-Callière est un musée in situ spécialisé en histoire et en archéologie urbaine. Le musée préserve et met en valeur le lieu de fondation de Montréal et comprend trois sites historiques et archéologiques classés d'envergure nationale (Québec et Canada) : La pointe à Callière, lieu de fondation (1642) ; La place Royale, $1^{\text {re }}$ place du marché (1676) ; La place de la Grande paix de Montréal (1701).

10. Regards, p. 109-110.

11. Magnago Lampugnani, V. Insight versus Entertainment: Untimely Meditations on the Architecture of Twentieth-century Art Museums. Sharon MacDonald, éd., A Companion to Museum Studies, Oxford, Blackwell Publishing Ltd, 2006, p. 252.

\section{RÉSUMÉS}

Depuis quelques années les musées québécois connaissent une hausse marquée de leur fréquentation. L'auteur analyse les raisons de cet engouement qui se produit pourtant dans un contexte financier délicat et face à une forte concurrence des industries culturelles. Différentes formes d'action sont ainsi mises en œuvre pour favoriser le décloisonnement du musée devenu lieu d'expérimentation et attirer le public.

\section{INDEX}

Mots-clés : Action culturelle, Québec, public 


\section{AUTEUR}

\section{KATY TARI}

Muséologue et historienne, directrice Collections-Programmes et service au public, Pointe-à-

Callière, cité d'archéologie et d'histoire de Montréal

ktari@pacmusee.qc.ca 